Direitos autorais distribuídos a partir $\mathrm{d}$ licença Creative Commons (CC BY-NC-SA - 4.0)

\title{
TEATRO E INTERMIDIALIDADE: UM ESTUDO DO ESPETÁCULO “QUANDO EU MORRER VOU CONTAR TUDO A DEUS"
}

\author{
Lysiane Cassia Baldo - baldolysiane@gmail.com \\ Universidade Estadual do Oeste do Paraná, Unioeste, Cascavel, Paraná, Brasil; https://orcid.org/0000-0002-4888-4365
}

\begin{abstract}
RESUMO: O Teatro ocidental nasce por meio da intermidialidade. Partindo das estruturas literárias para se desenvolver enquanto linguagem, por muitos séculos o teatro é entendido como enunciador do texto dramático. Ademais, em sua evolução, o teatro irá abraçar, desde cedo, outras linguagens artísticas. No entanto, todas essas possibilidades de entrelaçamentos serão articuladas intencionalmente e irão explodir nas experimentações do teatro contemporâneo, diminuindo os limites e criando problemáticas e novas conceituações sobre campos da arte até então inexplorados. Assim, analisaremos a proposta de construção do espetáculo 'Quando eu morrer vou contar tudo a Deus' (2019), do coletivo 'O Bonde’, que costura o trabalho dos atores com música, contação de histórias, dança e propõe uma visualidade singular por meio de vários elementos cenográficos. Além disso, a dramaturgia do espetáculo é concebida a partir de notícias de jornal e histórias reais, que tencionam a relação entre o real e o ficcional, trazendo novos dimensionamentos ao espectador. Sendo assim, o espetáculo propõe uma narrativa híbrida, que se atualiza por meio da interação entre estas diversas mídias e suportes no diálogo com os espectadores no tempo efêmero da cena teatral. Nosso objetivo é, portanto, investigar questões acerca do espetáculo e respectivas subjetividades na delimitação de um viés intermidiático para a construção da cena. Para delimitação do escopo de análise são utilizadas como base teórica as conceituações de Patrice Pavis, Chiel Kattenbelt e Silvia Fernandes.
\end{abstract}

PALAVRAS-CHAVE: Intermidialidade; Teatro Contemporâneo; Teatros do real.

\section{COLETIVO ‘O BONDE’ E ‘QUANDO EU MORRER VOU CONTAR TUDO A DEUS’ - CONTEXTUALIZAÇÃO}

O coletivo 'O Bonde' é um grupo teatral formado por artistas negros, oriundos da escola livre de teatro de Santo André. O grupo tem como pesquisa de linguagem o teatro negro e suas diásporas contemporâneas. Quando eu morrer vou contar tudo a Deus é o primeiro espetáculo do coletivo, estreado em março de 2019.

A dramaturgia do espetáculo é de Maria Shu, dramaturga e roteirista, cujo texto foi recentemente publicado na coletânea intitulada 'Dramaturgia Negra', que reúne 16 (dezesseis) textos de dramaturgos negros, sendo a primeira antologia de dramaturgia negra no Brasil, contribuindo, desta maneira, para a diminuição da lacuna histórica da dramaturgia produzida por autores negros nos meios acadêmico e literário.

O texto de Maria Shu é inspirado em notícias de jornal e trata de uma história real ocorrida em 2015, com o menino Abou, um garoto de 8 (oito) anos, da Costa do Marfim, que foi encontrado dentro 
de uma mala de viagem e identificado por uma máquina de raios-X, tentando ser levado a Ceuta, cidade autônoma da Espanha que faz fronteira com o norte da África. A história comoveu o mundo todo e também Maria Shu, que fez dela seu mote para a criação do texto, que tem como tema central a questão dos refugiados.

Já o título do texto - e também do espetáculo - remete a outro caso real, de uma criança síria de apenas 3 (três) anos de idade, vítima dos horrores da guerra, que ao ser resgatada muito ferida, poucos dias antes de morrer, proferiu estas palavras: "quando eu morrer vou contar tudo a Deus". O caso também repercutiu por todo o mundo.

Deste modo, a dramaturgia do espetáculo é concebida a partir de notícias de jornais e histórias reais, que tencionam a relação entre o real e o ficcional, estabelecendo uma relação intermídia e trazendo novos dimensionamentos ao leitor/espectador, opção muito recorrente em trabalhos contemporâneos.

Outro aspecto que ressalta o caráter intermidiático do espetáculo é a mistura de linguagens artísticas na composição da obra. As escolhas estéticas do grupo costuram o trabalho dos atores com música executada ao vivo, contação de histórias, dança e propõem uma visualidade singular por meio de vários elementos cenográficos (figurinos, cenário, objetos cênicos). Cada elemento selecionado vai colaborando para a produção de sentidos nesta narrativa híbrida, que se atualiza por meio da interação entre estas diversas mídias e suportes no diálogo com os espectadores no tempo efêmero da cena teatral.

Assim, tanto do ponto de vista dramatúrgico, quanto do ponto de vista da encenação, pretendemos discutir aqui, aspectos relacionados à intermidialidade de 'Quando eu morrer vou contar tudo a Deus' (2019).

\section{INTERMIDIALIDADE NA CONSTRUÇÃO DRAMATÚRGICA E NA CENA DO ESPETÁCULO QUANDO EU MORRER VOU CONTAR TUDO A DEUS}

A partir da experiência vivida como espectadora da obra aqui analisada e do diálogo desta com as conceituações de Pavis, Kattenbelt e Silvia Fernandes sobre teatro e intermidialidade, pretendo traçar uma análise da obra 'Quando eu morrer vou contar tudo a Deus' (2019).

Cabe iniciar lembrando que, embora os casos reais e sua dimensão política/social causem impactos e sejam fortes impulsos da dramaturgia e do espetáculo, aqui nos interessa também - e não com menor importância - a forma como ocorre a elaboração estética da obra, pois é só a partir desta, que o significado maior da criação artística emerge, tanto para os artistas quanto para o público.

A princípio, o que me chamou a atenção para a escolha deste espetáculo como objeto de análise foi justamente sua elaboração estética, pois meu olhar de artista está assim habituado. Porém, no momento seguinte, percebi que a elaboração estética está tão intrinsecamente ligada à temática, e que esta 
me toca profundamente, por sua urgência e necessidade. Neste sentido, é importante notar que o caráter intermidiático da obra (na esfera da cena e da dramaturgia) colabora tanto para a construção de sua elaboração estética, quanto para a enunciação das questões políticas e sociais que dela emergem.

Outro ponto que se destaca nesta obra é a abordagem de uma temática densa, difícil de ser "traduzida" em uma linguagem direcionada para crianças, público-alvo do trabalho. O termo "traduzida" fica entre aspas, justamente porque a concepção do espetáculo vê as crianças espectadoras como seres autônomos, capazes de criar suas próprias imagens e apreensão do espetáculo, sem que seja preciso explicar-lhes nada ou traduzir-lhes uma mensagem.

Esta concepção se aproxima do olhar recente da Sociologia da Infância, campo do conhecimento que surgiu somente a partir da década de 1980, para dar à criança o espaço que lhe é devido historicamente. Essa vertente entende a criança como diferente e não - necessariamente - como inferior ao adulto, o que fora por muito tempo propagado. Neste contexto, a criança é entendida como um sujeito social, que atribui significados e sentidos aos processos de socialização, criando com isso, sua própria cultura.

Desse modo, 'Quando eu morrer vou contar tudo a Deus' (2019) se coloca em uma posição de destaque no cenário do teatro para crianças no Brasil. Já que, infelizmente, ainda vemos uma tendência, nos trabalhos artísticos para a infância, em subestimar a capacidade de leitura das crianças, reduzir as possibilidades de diálogo e múltiplas leituras. Sobre isso, no artigo intitulado Fronteiras etárias no teatro: da demarcação à abertura (2000), Pupo irá fazer uma crítica contundente:

[...] o que se pode verificar é que a especificidade da dramaturgia e da encenação infantis não vem lhe assegurando nível de qualidade enquanto criação artística. Subjaz às representações mentais do adulto produtor do discurso teatral a imagem de um jovem espectador marcado por uma espécie de indigência de caráter intelectual. Uma encenação pobre, um texto recheado de lugares-comuns ou uma interpretação incipiente são veiculados sem maiores constrangimentos, na medida em que têm apenas crianças como alvo (PUPO, 2000).

Escapando dessa lógica e, justamente utilizando-se da intermidialidade como recurso também na encenação, 'Quando eu morrer vou contar tudo a Deus' cria inúmeros mecanismos que ampliam as possibilidades de leitura. No espetáculo, mesclam-se música, contação de histórias, dança e teatro, extrapolando as fronteiras de delimitação de linguagem, mesmo estando classificado como teatro. Sobre isso, Fernandes afirma que:

O teatro contemporâneo partilha com a dança, as artes plásticas e o cinema uma crise de identidade e uma indefinição de estatuto epistemológico. Nesse sentido, pode-se falar de experiências cênicas com demarcações fluidas de território, em que o 
embaralhamento dos modos espetaculares e a perda de fronteiras entre os diferentes domínios artísticos são uma constante (FERNANDES, 2011, p. 11).

Percebe-se que a obra não se preocupa em obedecer às classificações, o que é característico da linguagem contemporânea. Mesmo sendo indicado ao público infantil, o trabalho agrega sem esforço o público adulto, pois proporciona muitas camadas de leitura.

Combinando música, narração, dança e vários elementos cênicos, o espetáculo vai traçando a trajetória do personagem Abou, que é também o narrador desta história. Quatro atores narradores se revezam na interpretação do Abou, o que revela uma estratégia de construção cênica interessante. Pois, sem ressaltar um único ator como o personagem protagonista, o trabalho sugere a ideia de que todos nós podemos estar em algum momento no lugar de Abou, colaborando para o sentimento de alteridade. Sobre isso, citamos Fernandes:

[...] o desejo do real, onipresente na pesquisa teatral contemporânea, não é mera investigação de linguagem. Ao contrário, ele parece testemunhar a necessidade de abertura do teatro à alteridade, ao mundo e à história, em detrimento do fechamento da representação, predominante na década de 80 (FERNANDES, 2013, p. 4).

A história caminha desde a saída de Abou de seu país e perpassa toda a trajetória dele, até sua chegada ao que ele chama de "país Europa", quando a mala é aberta e o menino é encontrado. Essa travessia vai sendo contada de forma poética e, em alguns momentos, com um peso que não chega a afastar as crianças da plateia, mas lhes traz para um lugar mais silencioso, de dúvida e medo, onde está Abou. Impossível não confrontar a encenação com as condições pelas quais passou o Abou real, que é o “motivo” deste espetáculo. E é por meio da ficção que enxergamos aqui esta difícil realidade.

Neste espetáculo, essa emergência do real fica ainda mais nítida quando, em alguns momentos, a narrativa da história de Abou é interrompida pela 'rádio', metaforizada por um microfone num pedestal e uma placa na qual se vê escrito: "no ar", que surgem junto com os atores, todos atrás de uma pilha feita de malas, enunciando notícias reais sobre diversos casos de refugiados pelo mundo todo. Ainda sobre essa relação ficção/realidade no teatro contemporâneo, Fernandes afirma:

Reportando-se a José Antonio Sanchez, um dos maiores estudiosos do assunto, mapeiam as experiências diversificadas do teatro que busca o real como elemento, mencionando duas vertentes em que se configura. Uma delas toma o real como elemento temático, introduzindo inovações na dramaturgia ao tecê-la a partir da compilação de materiais e documentos da realidade. A outra privilegia o real como matéria da experiência cênica, e acontece quando a realidade bruta irrompe no tecido ficcional para seccioná-lo, desestabilizá-lo e abrir brechas a diversos tipos de manifestação performativa (FERNANDES, 2013, p. 11). 
Desta maneira, podemos entender o espetáculo 'Quando eu morrer vou contar tudo a Deus' (2019) sob a primeira vertente explicitada por Fernandes. O real se configura na dramaturgia como elemento temático, produzindo um "peso" e um "calor" diferentes também na sua passagem para a cena. No entanto, o espetáculo abre brechas, pelo próprio exemplo da rádio - de irrupção mais direta do tecido ficcional - mas ainda não chega a ser uma manifestação de caráter performativo, mantendo as características centrais do teatro dramático.

A mala é o objeto central, que conduz a ação dos atores. No início da narrativa, ainda em seu país, Abou pede ao pai uma cachorrinha, seu mais precioso desejo. Sem poder satisfazer a necessidade do garoto, o pai lhe traz a dura notícia de que eles não teriam como alimentar o animal. No lugar da cachorra, o pai lhe dá uma mala velha para brincar, a qual ele logo dá o nome de Ilê, e transforma em cachorra (na sua imaginação). Durante toda a travessia, quando Abou está dentro da mala, ele a vê como cachorra, sente sua respiração e assim fica acolhido nas entranhas de Ilê.

A ação dos atores e o tão conhecido jogo de ressignificação de um objeto em cena dão vida à cachorra Ilê nas malas manipuladas pelos atores durante as cenas. Uma fivela se transforma em "rabinho", um zíper em boca e assim por diante.

A sonoplastia do espetáculo é executada ao vivo, a partir de variados instrumentos percussivos e também ao som do violão. Em alguns momentos, os atores também cantam e dançam, resgatando canções e ritmos da cultura africana. A música acaba sendo quase como um personagem do espetáculo, e tem um peso muito importante na construção da cena.

Figura 1 - Músicos do espetáculo

Fonte: Arquivo do grupo (2019). Reprodução autorizada

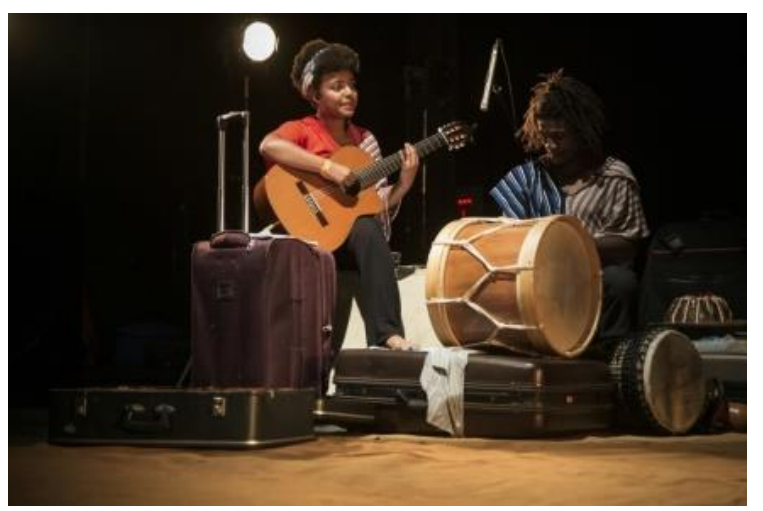

Sobre a influência da música no espetáculo, Pavis (2010, p. 130) afirma: “[...] aninhada no espetáculo, ela irradia, sem que se saiba muito bem o quê. Influencia nossa percepção global, mas não saberíamos dizer que sentido ela suscita ao certo. Ela cria uma atmosfera que nos torna particularmente receptivos à representação. É como uma luz da alma que desperta em nós". 
O trabalho dos atores está fortemente interligado com todos os elementos da peça. Também é possível observar que o sentido de coletividade permeia todo o trabalho, já que as atuações vão se complementando, tanto na divisão do personagem Abou, quanto nas de outros personagens e, principalmente, na criação de imagens, a partir da manipulação das malas. Assim, a visualidade do espetáculo gera a produção de signos diversos para o público.

Além dos objetos manipulados pelos atores, a cenografia conta também com um painel de fundo, o qual, no começo do espetáculo, é formado por uma bela imagem de um grande baobá e, no transcorrer da viagem de Abou, vai se transformando.

São várias malas abertas, com a imagem pintada, que vão sendo fechadas gradativamente, conforme a viagem do personagem avança. Assim, as relações do personagem com esta difícil trajetória são também metaforizadas pela cenografia que, magicamente, se modifica aos olhos do público.

Figura 2 - Cenografia ao fundo no início do espetáculo

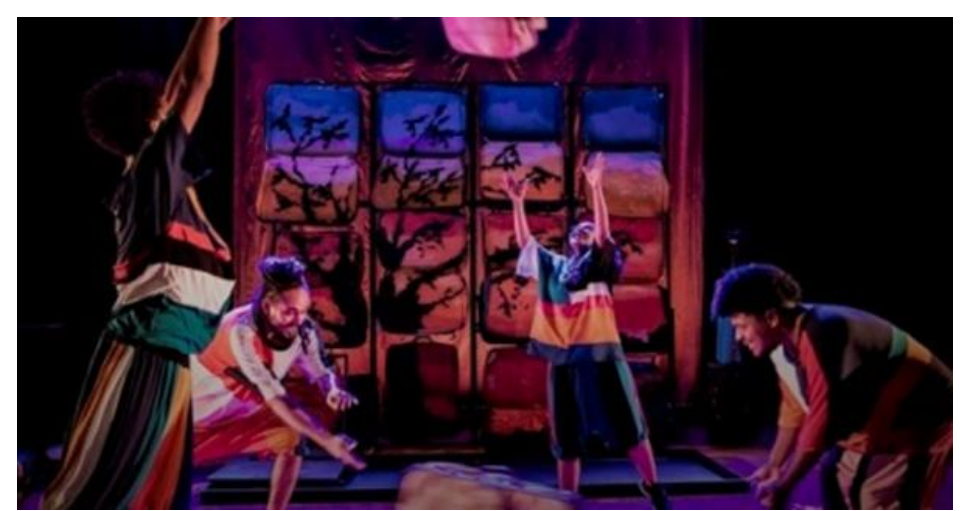

Fonte: Arquivo do grupo (2019). Reprodução autorizada

Figura 3 - Cenografia ao fundo no final do espetáculo

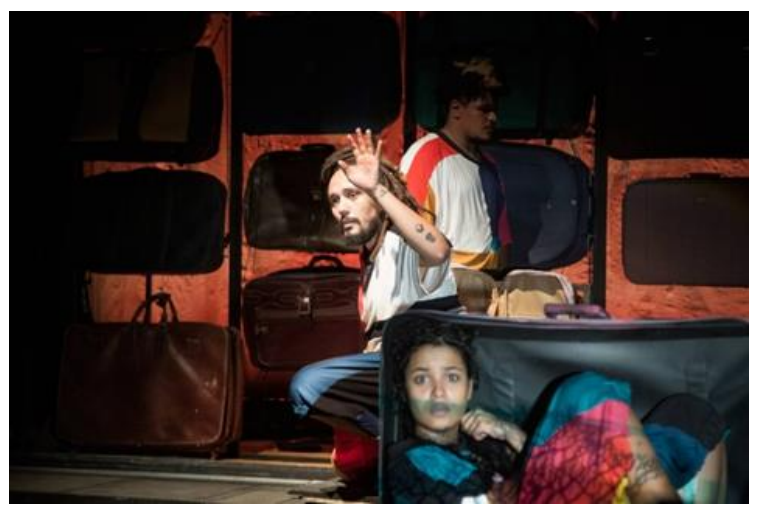

Fonte: Arquivo do grupo (2019). Reprodução autorizada

Outra escolha do grupo é representar os pais de Abou utilizando dois bonecos grandes, que são manipulados por um ou mais atores nas cenas em que estão presentes. Também se torna uma estratégia 
interessante, haja vista que, para as crianças pequenas, ficam bem evidenciadas nos bonecos as figuras do pai e da mãe. Tanto na construção dos bonecos, quanto do cenário, objetos cênicos e figurinos, percebese que há um estudo de cores e formas que remetem à cultura africana, compondo a visualidade do trabalho.

Fica também evidente, no trabalho do grupo, como a capacidade de imaginação da criança, representada pelo personagem Abou, neste lugar do sonho e de fantasia, é o mais seguro espaço de refúgio, como uma alternativa para escapar do real, provocado pelas condições tão adversas que se estabelecem, nas demarcações de fronteiras não só geográficas, mas também culturais, políticas e, principalmente, sociais.

Sem dúvida, essa percepção se fortalece pelo lugar de fala dos artistas que fazem parte do grupo. Um coletivo que se constitui negro não por acaso e, de onde, possivelmente, muitas histórias reais de luta e resistência fazem diálogo com todo o espaço de ficção construído neste belo trabalho.

Como a dramaturgia traz Abou como o próprio narrador de sua história, o espetáculo, em muitos momentos, ganha tons de contação de histórias, num sentido de compartilhamento de segredos de Abou com o público, criando um enlace que seduz crianças e adultos.

Felizmente, o final desta história é de esperança. Abou reencontra os pais, faz aniversário e satisfaz seus desejos mais profundos: comer um pudim malva, que ele, no transcorrer da história, deseja muitas vezes, mas não o tem, e ganhar uma cachorra de verdade, representada no espetáculo por um boneco cachorra, que tira risos da plateia. Desejos simples, mas que aqui se configuram como o lugar de aconchego e sonhos do menino Abou.

\section{TEATRO, INFÂNCIA E INTERMIDIALIDADE}

É então sob essa perspectiva híbrida, de entrelaçamento entre diferentes linguagens (teatro, dança, música, contação de histórias, artes visuais) e por sua opção dramatúrgica que se dimensiona pelo real, que o espetáculo ganha sua força cênica. Nesta direção, Kattenbelt compreende o teatro como o grande palco da intermidialidade. Sobre isso ele afirma:

[...] nenhuma forma de teatro específica ou performance é uma completa realização da essência do teatro. A consequência disso é que tão logo duas artes específicas ou mais se conectam uma à outra na mesma obra de arte, elas cruzam e ultrapassam seus momentos constitutivos (KATTENBELT, 2012, p. 119).

Neste sentido, para Kattenbelt, o teatro é, entre todas as artes, a de mais complexa delimitação, por seu poder de atrair e abraçar as demais linguagens artísticas em sua forma, conforme atesta:

Travessias, Cascavel, v. 15, n. 2, p. 84-92, maio/ago. 2021. DOI: https://doi.org/10.48075/rt.v15i2.27735 
[...] podemos definir o teatro como a arte da presença física (comunicação face a face numa situação aqui e agora) e da expressão em palavras, gestos/movimentos e sons. Esta é a base de todas as outras artes na medida em que elas se distinguem e se diferenciam em literatura, sob a primazia dos pensamentos expressos em palavras escritas; em artes visuais, sob a primazia das intuições sensuais expressas em imagens congeladas; e em música, sob a primazia das sensações expressas em sons. O teatro é a única arte capaz de incorporar todas as outras artes sem depender delas para ser teatro (KATTENBELT, 2012, p. 120).

O espetáculo ‘Quando eu morrer vou contar tudo a Deus’ (2019) cumpre muito bem essa função intermidiática, propondo ao espectador uma experiência ampla, já que provoca os vários sentidos (auditivo, visual, cinestésico), muito embora opte por não tirar o espectador do conforto da cadeira na perspectiva bidimensional do palco italiano e também busque manter a estrutura tradicional do teatro dramático.

Contudo, podemos sem dúvida encontrar no trabalho do grupo uma referência significativa, a partir de um trabalho provocativo no que diz respeito ao teatro que se direciona para crianças, principalmente pelas relações que estabelece em relação ao tema proposto e aos seus recursos estéticos, como pudemos perceber brevemente nesta análise.

Neste contexto, percebemos quão ampla é a experiência teatral e suas formas de abordagem, tão múltiplas que havemos de concordar com Kattenbelt quando este afirma: "A partir disso, estamos a um passo de reivindicar o teatro como o paradigma de todas as artes e, portanto, uma hipermídia que é capaz de incorporar todas as outras artes e mídias" (KATTENBELT, 2012, p. 119).

\section{REFERÊNCIAS}

CANDIDO, Antonio. Literatura e Sociedade. 9. ed. Ouro sobre Azul: Rio de Janeiro, 2006.

FERNANDES, Silvia. Experiências do real no teatro. Sala Preta, v. 13, n. 2, p. 3-13, dez. 2013.

FERNANDES, Silvia. Teatralidade e performatividade na cena contemporânea. Repertório, Salvador, n. 16, p. 11-23, 2011.

KATTENBELT, Chiel. O teatro como arte do performer e palco da intermidialidade. In: DINIZ, Thais; VIEIRA, André. Intermidialidade e estudos interartes: desafios da arte contemporânea. Belo Horizonte: Rona Editora, 2012. p. 115-130.

PAVIS, Patrice. A análise dos espetáculos: teatro, mímica, dança, dança-teatro, cinema. São Paulo: Perspectiva, 2010.

PUPO, Maria Lúcia de Souza Barros. Fronteiras etárias no teatro: da demarcação à abertura. Revista USP, São Paulo, n. 44, p. 335-340, 2000. Disponível em: http://www.revistas.usp.br/revusp/article/view/30100. Acesso em: 22 jun. 2019. 


\title{
Title
}

Theater and intermidiality: a study of the spectacle "When I die I will tell God everything".

\begin{abstract}
Occidental theater is born through intermediality. Starting from literary structures to develop itself as a language, for many centuries the theater has been understood as an enunciator of the dramatic text. Furthermore, in its evolution, theater will embrace, from an early age, other artistic languages. However, all these possibilities of entanglement will be intentionally articulated and will expand in the experiments of contemporary theater, reducing the limits and creating problematic and new concepts about art fields, unexplored until then. That being said, we will analyze the construction proposal of the spectacle 'When I die, I'll tell God everything' (2019), by the collective 'O Bonde', which links the work of the actors with music, storytelling, dance and proposes a unique visuality through several scenic elements. In addition, the dramaturgy of the spectacle is conceived from newspaper news and real stories, which tenses the relationship between the real and the fictional, bringing new dimensions to the spectator. Therefore, the spectacle proposes a hybrid narrative, which is updated through the interaction between these different media and supports in the dialogue with spectators in the ephemeral time of the theatrical scene. Our objective is, therefore, to investigate questions about the spectacle and respective subjectivities in the delimitation of an intermediate bias for the construction of the scene. To delimit the scope of analysis, the concepts of Patrice Pavis, Chiel Kattenbelt and Silvia Fernandes are used as a theoretical basis.
\end{abstract}

\section{Keywords}

Intermediality; Contemporary Theater; Theaters of the real.

Recebido em: 06/07/2021.

Aceito em: 23/08/2021. 